\title{
Evaluation of Demands and Needs For Dental Care in a Sample of the Turkish Population
}

Filiz Pekinera

Birsay Gumru

Mehmet Oguz Borahan ${ }^{b}$

Emre Aytugar ${ }^{c}$

\section{ABSTRACT}

Objectives: To evaluate the demands and needs for dental care and to identify the level of dental and periodontal status in patients of different age groups visiting the Faculty of Dentistry, Marmara University, Istanbul, Turkey.

Methods: A total of 1000 first-visit patients (517 female and 483 male) were examined and questioned. The main complaint of each patient was recorded and considered to be a measure of demand for dental care. The World Health Organization's (WHO) basic methods were used to determine the tooth-based and orthodontic normative treatment needs. Periodontal status was determined by using the Community Periodontal Index of Treatment Needs (CPITN). In addition, prosthetic normative needs were assessed.

Results: This study showed that patients in different age groups required different treatments and had different main complaints. In total, 89.3, 74.1 and 57.7\% of the patients named periodontal, restorative and prosthetic care as their main complaint, respectively. Approximately $21 \%$ of the total did not need restorations and extractions, and only $12 \%$ of the sample did not have a normative periodontal treatment need. About half of subjects needed fixed partial dentures.

Conclusions: Normative treatment needs of patients were very high. Therefore, a new national strategy for oral health must be devised for Turkey. This study can assist in setting the baseline for that strategy. (Eur J Dent 2010;4:143-149)

Key words: Oral hygiene; Periodontal status; Dental treatment demands; Treatment needs.

a DDS, PhD, Assistant Professor, Department of Oral Diagnosis and Radiology, Faculty of Dentistry, Marmara University, Istanbul, Turkey.

b DDS, PhD, Research Associate, Department of Oral Diagnosis and Radiology, Faculty of Dentistry, Marmara University, Istanbul, Turkey. Research Assistant, Department of Oral Diagnosis and Radiology, Faculty of Dentistry, Marmara University, Istanbul, Turkey.
Corresponding author:

Dr. Filiz Pekiner,

Marmara University, Faculty of Dentistry, Department of Oral Diagnosis and Radiology, Buyukciftlik Sok. No: 6 34365 Nisantasi, Sisli, Istanbul, Turkey.

Phone: +90 (212) 2319120

Fax: +90 (212) 2465247

E-mail: fpekinerdyahoo.com 


\section{INTRODUCTION}

In recent years, rapid changes have occured in the patterns of oral diseases across countries. In developing countries, oral disease data are primarily collected to aid authorities planning health care systems. These epidemiological data may allow for an improved understanding of the nature of oral diseases and changing disease patterns at the population level because these studies are conducted in populations that so far have had very limited access to formal oral health care. ${ }^{1-9}$

Studies concerning oral health care of the population are scarce in Turkey. There are only a few reports providing information about dental care treatment needs. ${ }^{10-13}$ In contrast, there are no reports about the treatment demands for dental care.

There are various definitions of need. ${ }^{14}$ The definition that is most often quoted is the taxonomy proposed by Bradshaw ${ }^{15}$ that identifies four categories of need:

1. Normative need, defined by the professional.

2. Felt need, which is equated with want.

3. Expressed need or demand; felt need is converted into action by seeking care.

4. Comparative need, which is assessed by comparing care received by different people with similar characteristics.

The concept of need is central to the planning, provision and evaluation of health services. For effective planning and evaluation of any health service, both estimates of levels of need as well as demand for treatment should be taken into account. ${ }^{14}$

The aim of the present study was to determine the demands and needs for dental care and to identify the level of dental and periodontal status of patients from different age groups who visited Marmara University, Faculty of Dentistry, Istanbul, Turkey.

\section{MATERIALS AND METHODS}

The study group consisted of 1000 patients, 16 65 years old, who sought treatment for the first time at Faculty of Dentistry of Marmara University during a period of 12 months from 2004 to 2005. All patients were examined in the Department of Oral Diagnosis and Radiology. Personal data of the patients and their main complaint or main reason for visiting were recorded. An initial examination was conducted to determine the treatment necessary to address the main complaint. This was followed by an assessment of normative treatment needs of each patient.

The WHO's basic methods were used to determine the tooth status and the tooth-based treatment needs, ${ }^{16}$ and the Community Periodontal Index for Treatment Need (CPITN) ${ }^{10,17}$ was used to record each patient's scores. The CPITN scores are: 0 = healthy, 1 = bleeding on gentle probing, 2 = calculus, 3 = shallow pocketing of 4 or $5 \mathrm{~mm}$, and $4=$ deep pockets of $6 \mathrm{~mm}$ or more. The clinical examination of the patients was carried out using a dental mirror, an explorer and the periodontal probe recommended by WHO.

Criteria for the assessment of incomplete dentition were based on the concept of the shortened dental arch proposed by Kayser and Witter. ${ }^{18}$ They suggested that a minimum of 20 teeth is sufficient to meet oral functional demands, and therapy should be aimed at preserving or replacing teeth in the premolar and anterior regions. If there are less or will be less than 20 teeth after the indicated extractions, they deemed a person to be in need of a partial denture (presence of tooth spaces anterior to the second premolars). A full denture was indicated when an arch was edentulous or had only one or two remaining teeth. Orthodontic treatment was indicated in the presence of crowding or spacing of more than $4 \mathrm{~mm}$, anterior crossbite, openbite and maxillary overjet estimated to be $9 \mathrm{~mm}$ or more. ${ }^{14}$

Four dentists participated in the survey and calibration trials were performed initially to ensure an inter-examiner consistency of at least $85 \%$ in recording. For calibration, 20 patients were evaluated and not included in the main study. Inter-examiner agreement was measured by $\mathrm{Co}^{-}$ hen's Kappa statistic.

Statistical analyses were performed using the Statistical Package for Social Sciences ISPSS Inc., Chicago, IL, USA) 10.0 programme for Windows. Descriptive statistical methods (mean, standard deviation) were used for the evaluation of the data. The quantitative data was compared using the chisquared test, and the value of $\mathrm{P}<.05$ was considered significant.

\section{RESULTS}

The sample surveyed consisted of 517 females (51.7\%) and 483 males (48.3\%). Table 1 shows the 
distribution of subjects who required treatment according to their age groups and gender. A higher percentage of females than males sought treatment except in the 16 and $>65$ age groups.

The percentage distribution of the main complaint in subjects in relation to age groups is shown in Table 2. When the age groups were considered separately, malocclusion was the the most common complaint in the 16 age group (90.5\%) and a similar trend in treatment demand was observed in the 17-34 age group (54.4\%). Tooth decay was the main complaint in the 17-34 and 35-44 age groups. The 35-44 and 45-64 age groups mainly required fixed partial dentures and complained of bleeding gums, whereas removable dentures was the most common demand in the $>65$ age group. Painful gums was the most common complaint in the 35-44 age group. Statistically significant differences were found for fixed and removable dentures, malocclusion, bleeding gums and painful gums, respectively, according to age $(P<.01$ and $\mathrm{P}=0.002$ ).

Table 1. Distribution of subjects according to age group and gender.

\begin{tabular}{lcccccc}
\hline \multicolumn{7}{c}{ Age group (years) } \\
& $16 \mathrm{n}(\%)$ & $17-34 \mathrm{n}(\%)$ & $35-44 \mathrm{n}(\%)$ & $45-64 \mathrm{n}(\%)$ & $>65 \mathrm{n}(\%)$ & Total $\mathrm{n}(\%)$ \\
\hline Female & $63(47.7)$ & $169(51.7)$ & $201(53.9)$ & $74(51.7)$ & $10(40.0)$ & $517(51.7)$ \\
Male & $69(52.3)$ & $158(48.3)$ & $172(46.1)$ & $69(48.3)$ & $15(60.0)$ & $483(48.3)$ \\
\hline
\end{tabular}

Table 2. Percentage distribution of the main complaint in subjects according to age group.

\begin{tabular}{|c|c|c|c|c|c|c|}
\hline \multirow[b]{2}{*}{ Main complaint } & \multicolumn{6}{|c|}{ Age group (years) } \\
\hline & $\begin{array}{c}16 \\
\text { (n=132) }\end{array}$ & $\begin{array}{c}17-34 \\
(n=327)\end{array}$ & $\begin{array}{c}35-44 \\
(n=373)\end{array}$ & $\begin{array}{c}45-64 \\
(n=143)\end{array}$ & $\begin{array}{c}>65 \\
(n=25)\end{array}$ & $\begin{array}{c}\text { Total } \\
(n=1000)\end{array}$ \\
\hline Decayed teeth & 6.8 & 15.6 & 15.0 & 11.2 & 12.0 & 13.5 \\
\hline Toothache & 0.0 & 4.6 & 2.4 & 4.2 & 0.0 & 3.0 \\
\hline Stains & 0.0 & 0.6 & 0.8 & 0.7 & 0.0 & 0.6 \\
\hline Fixed dentures* & 7.6 & 32.1 & $69.7^{*}$ & $61.5^{*}$ & 36.0 & 47.2 \\
\hline Removable dentures* & 0.0 & 1.2 & 2.4 & 28.0 & $60.0 *$ & 6.8 \\
\hline Malocclusion* & $90.5^{*}$ & $54.4^{*}$ & 0.0 & 0.0 & 0.0 & 30.6 \\
\hline Extraction need & 0.8 & 1.2 & 3.2 & 1.4 & 4.0 & 2.0 \\
\hline Fractured tooth & 0.0 & 0.0 & 0.0 & 0.7 & 0.0 & 0.1 \\
\hline Swelling & 0.0 & 0.3 & 0.0 & 0.0 & 0.0 & 0.1 \\
\hline Bleeding gums* & 6.8 & 12.2 & $24.4^{*}$ & $22.4^{*}$ & 8.0 & 17.4 \\
\hline Painful gums** & 0.0 & 0.0 & $3.5^{* *}$ & 2.8 & 0.0 & 1.7 \\
\hline Mobility & 0.0 & 1.2 & 2.4 & 3.5 & 4.0 & 1.9 \\
\hline Sensitivity & 0.0 & 0.3 & 0.5 & 1.4 & 0.0 & 0.5 \\
\hline
\end{tabular}

$\chi^{2}$ : chi-square test

*: $\mathrm{P}<.01,{ }^{* *}: \mathrm{P}=0.002$

April 2010 - Vol.4 
and endodontic treatments were more necessary for those in the 17-34 age group than the others (59.3 and 5.8\%, respectively). Similarly, people in the 35-44 age group needed more extractions due to caries and periodontal problems than those in the other groups (35.9 and 4.3\%, respectively). None of the patients in the $>65$ age group needed extraction because of periodontal, endodontic and other reasons.

Upper and/or lower full denture treatments were needed by members of the 45-64 and $>65$ age groups. A higher percentage of subjects in the $>65$ age group $(44.0 \%)$ needed partial dentures compared to those in other age groups. Orthodontic treatment was needed by $90.2 \%$ of the subjects in the 16 age group, and $76.9 \%$ of the $35-44$ age group needed fixed dentures (Table 5).

A larger percentage of subjects in the 17-34 age group had a CPITN score of 1 . However, those in the 45-64 and 35-44 age groups were more likely to have scores of 3 and 4 . A statistically significant difference was observed among CPITN scores and age groups $(P<.01$ and $P<.0001)$ (Table 6$)$.

In particular, the percentages of subjects in the 35-44 age group with periodontal scores of $1,2,3$ and 4 were higher than those of other age

Table 3. Percentage distribution of type of care required for the main complaint of subjects according to age group.

\begin{tabular}{|c|c|c|c|c|c|c|}
\hline \multirow[b]{2}{*}{ Type of care } & \multicolumn{6}{|c|}{ Age group (years) } \\
\hline & $\begin{array}{c}16 \\
\text { (n=132) }\end{array}$ & $\begin{array}{c}17-34 \\
(n=327)\end{array}$ & $\begin{array}{c}35-44 \\
(n=373)\end{array}$ & $\begin{array}{c}45-64 \\
(n=143)\end{array}$ & $\begin{array}{c}>65 \\
(n=25)\end{array}$ & $\begin{array}{c}\text { Total } \\
(n=1000)\end{array}$ \\
\hline Prosthetic*** & 7.6 & 35.8 & 79.4 & $90.9 * * *$ & $96.0 * * *$ & 57.7 \\
\hline Restorative* & 70.5 & $77.7^{*}$ & $76.1^{*}$ & 67.8 & 52.0 & 74.1 \\
\hline Surgical** & 3.0 & 5.2 & 6.2 & $13.3^{* *}$ & $16.0^{* *}$ & 6.7 \\
\hline Periodontal*** & 64.4 & 89.0 & $96.2^{* * *}$ & $95.8 * * *$ & 84.0 & 89.3 \\
\hline Orthodontic*** & $94.8 * * *$ & $57.8 * * *$ & 0.0 & 0.0 & 0.0 & 32.5 \\
\hline
\end{tabular}

$\chi^{2}$ : chi-square test

$*: \mathrm{P}<.01,{ }^{* *}: \mathrm{P}<.001,{ }^{* * *}: \mathrm{P}<.0001$

Table 4. Percentage distribution of tooth-based normative treatment needs in subjects according to age group.

\begin{tabular}{|c|c|c|c|c|c|c|}
\hline & \multicolumn{6}{|c|}{ Age group (years) } \\
\hline & $\begin{array}{c}16 \\
(n=132)\end{array}$ & $\begin{array}{c}17-34 \\
(n=327)\end{array}$ & $\begin{array}{c}35-44 \\
(n=373)\end{array}$ & $\begin{array}{c}45-64 \\
(n=143)\end{array}$ & $\begin{array}{c}>65 \\
(n=25)\end{array}$ & $\begin{array}{c}\text { Total } \\
(n=1000)\end{array}$ \\
\hline No need for restoration or extraction & 48.0 & 17.8 & 16.8 & 10.4 & 3.2 & 20.7 \\
\hline Extraction-caries & 14.4 & 30.3 & 35.9 & 32.9 & 28.0 & 30.6 \\
\hline Extraction-periodontal & 0.0 & 0.9 & 4.3 & 2.3 & 0.0 & 2.3 \\
\hline Extraction-other & 3.8 & 4.3 & 2.7 & 1.4 & 0.0 & 3.1 \\
\hline Endodontics & 1.5 & 5.8 & 3.8 & 2.1 & 0.0 & 3.8 \\
\hline Restoration & 28.0 & 59.3 & 36.4 & 50.3 & 40.0 & 38.9 \\
\hline
\end{tabular}

Table 5. Percentage distribution of normative prosthetic and orthodontic needs in subjects according to age group.

\begin{tabular}{|c|c|c|c|c|c|c|}
\hline & \multicolumn{6}{|c|}{ Age group (years) } \\
\hline & $\begin{array}{c}16 \\
(n=132)\end{array}$ & $\begin{array}{c}17-34 \\
(n=327)\end{array}$ & $\begin{array}{c}35-44 \\
(n=373)\end{array}$ & $\begin{array}{c}45-64 \\
(n=143)\end{array}$ & $\begin{array}{c}>65 \\
(n=25)\end{array}$ & $\begin{array}{c}\text { Total } \\
(n=1000)\end{array}$ \\
\hline Upper and lower full dentures & 0.0 & 0.0 & 0.0 & 0.7 & 12.0 & 0.4 \\
\hline Upper or lower full dentures & 0.0 & 0.0 & 0.0 & 2.8 & 4.0 & 0.5 \\
\hline Partial dentures & 0.0 & 0.3 & 4.0 & 22.5 & 44.0 & 6.9 \\
\hline Fixed dentures & 7.6 & 34.3 & 76.9 & 64.1 & 36.0 & 50.9 \\
\hline Orthodontics & 90.2 & 57.8 & 0.0 & 0.0 & 0.0 & 30.8 \\
\hline
\end{tabular}


groups $(38.8 \%, 40.1 \%, 45.4 \%$ and $46.4 \%$, respectively). Periodontal treatment needs, as assessed using CPITN, indicated that $67.6 \%, 17.6 \%$ and $2.8 \%$ of the total population needed oral hygiene instruction, scaling and periodontal surgery, and only $12 \%$ had no treatment need. Statistically significant differences were observed for normative periodontal treatment needs according to age $(\mathrm{P}<.0001)$ (Table 7).

\section{DISCUSSION}

Patients' perception of need frequently gives rise to a demand for health care. Patients are often unaware of the treatment options available and depend on the health care provider to suggest the appropriate care for their conditions.

This study, which is the first to evaluate the general situation regarding the demands for dental care of patients visiting Marmara University, Faculty of Dentistry in Istanbul, Turkey, showed that patients in different age groups requested different treatments and reported different main complaints. For example, in the 16 age group, malocclusion was the most common complaint, and patients in that group requested orthodontic treatment. In addition, the majority of patients demanded treatment for fixed dentures, malocclusion, bleeding gums and decayed teeth, respectively. In previous studies, Ekanayake et al ${ }^{14}$ revealed that the majority of patients demanded treatment for decayed teeth in Sri Lanka. Similar studies reported that toothache and pain due to dental caries and periodontal diseases were the most common causes of requested treatments. ${ }^{19-21}$

It is the obligation of a dentist not only to provide care for the presenting complaint of patients but also to make them aware of and provide treatment for any other condition that is diagnosed during a routine dental examination. This is necessary as it has been shown that patients are unable to assess their dental treatment needs accurately. Assessment of normative needs in patients who seek dental care at an institution is therefore important as such data could be used to estimate the resources and manpower required to meet the needs of patients. ${ }^{14,22}$

A less complex and internationally established method of estimating levels of periodontal conditions in populations is the widely used WHO CPITN, which has become an established index and has generated considerable data to identify levels of

Table 6. Percentage distribution of CPITN scores in subjects according to age group.

\begin{tabular}{lcc|ccc}
\hline Age group lyears) & Score $0^{* *}$ & Score $1^{* *}$ & Score $2^{* *}$ & Score $3^{* *}$ & Score 4* \\
\hline 16 & $40.8^{* *}$ & 10.4 & 9.7 & 6.3 & 0.0 \\
$17-34$ & 33.3 & $35.3^{* *}$ & $33.1^{* *}$ & 23.9 & 17.9 \\
$35-44$ & 15.0 & 38.8 & 40.1 & $45.4^{* *}$ & $46.4^{*}$ \\
$45-64$ & 5.8 & 13.6 & 15.0 & $21.5^{* *}$ & $28.6^{*}$ \\
$>65$ & 5.0 & 1.9 & 2.0 & 2.9 & $7.1^{*}$ \\
Total & 12.0 & 67.5 & 85.2 & 20.5 & 2.8 \\
\hline
\end{tabular}

$\chi^{2}:$ chi-square test

$*: \mathrm{P}<.01, * *: \mathrm{P}<.0001$

Table 7. Percentage distribution of periodontal treatment needs in subjects according to age group.

\begin{tabular}{|c|c|c|c|c|c|c|}
\hline & \multicolumn{6}{|c|}{ Age group (years) } \\
\hline & $\begin{array}{c}16 \\
(n=132)\end{array}$ & $\begin{array}{c}17-34 \\
(n=327)\end{array}$ & $\begin{array}{c}35-44 \\
(n=373)\end{array}$ & $\begin{array}{c}45-64 \\
(n=143)\end{array}$ & $\begin{array}{c}>65 \\
(n=25)\end{array}$ & $\begin{array}{c}\text { Total } \\
(n=1000)\end{array}$ \\
\hline No treatment needed* & $37.1^{*}$ & 12.2 & 4.8 & 4.9 & 24.0 & 12.0 \\
\hline $\mathrm{OH} I^{*}$ & 53.0 & $73.1^{*}$ & 70.2 & 64.3 & 52.0 & 67.6 \\
\hline Scaling* & 9.8 & 13.1 & 21.4 & $25.2^{*}$ & 16.0 & 17.6 \\
\hline Periodontal surgery* & 0.0 & 1.5 & 3.5 & $5.6^{*}$ & $8.0 *$ & 2.8 \\
\hline
\end{tabular}

$\chi^{2}:$ chi-square test

*: $\mathrm{P}<.0001$

April 2010 - Vol.4 
periodontal conditions of populations for which specific interventions might be considered. ${ }^{10,13}$ Therefore, we used this method to determine periodontal conditions of patients.

Of the 1000 patients examined, $12 \%$ were periodontally healthy (CPITN score 0). However, 67.5\% had gingival bleeding (CPITN score 1) and $85.2 \%$ had calculus (CPITN score 2). These findings implied that it is important that all age groups, except the $>65$ group, be assessed to find out their periodontal health status. Consistent with CPITN data reported, the present survey demonstrated high levels of gingival bleeding and dental calculus. . $^{50-12}$

This study revealed that the predominant need was for periodontal care $(88 \%)$, followed by restorative $(61.1 \%)$ and prosthetic care (fixed dentures, $49.1 \%$ ), respectively. Normative treatment needs detected were similar to the demand for periodontal treatment. However, requests for restorative and prosthetic treatments were found to be much higher than those for normative treatment. These results showed that patients' awareness about oral health is very good. Only $6.7 \%$ of all patients demanded surgical treatment. Unfortunately, the percentage distribution of surgical normative treatment needs in patients was very high. Correct information and knowledge about oral health is necessary to enable individuals to make appropriate decisions regarding necessary dental treatment. ${ }^{23}$

The patients from different age groups needed different treatments. Normative prosthetic needs were especially high for those in older age groups. On the other hand, the need for normative orthodontic care was higher for younger patients 116 and 17-34 age groups). These treatments are more expensive in private clinics than in a dentistry faculty in Turkey. Therefore, our dentistry faculty can expect a high demand for oral health care.

\section{CONCLUSIONS}

The present study included the following findings:

- Patients' expressed treatment needs lor main complaints) and normative treatment needs varied in relation to age groups. The majority of patients demanded treatment for fixed dentures, malocclusion, bleeding gums and decayed teeth. Normative prosthetic needs were higher for the older participants, and orthodontic needs were higher for those in the younger age groups.
- High levels of gingival bleeding and dental calculus were demonstrated, and only $12 \%$ of the sample was found to be periodontally healthy with no periodontal treatment needs.

- Periodontal treatment demand and normative periodontal treatment needs were revealed to be similar. In contrast, restorative and prosthetic treatment demands were found to be higher and surgical treatment demands to be lower compared to normative needs.

\section{REFERENCES}

1. Montal S, Tramini P, Triay JA, Valcarcel J. Oral hygiene and the need for treatment of the dependent institutionalised elderly. Gerodontology 2006;23:67-72.

2. Hawkins RJ, Main PA, Locker D. Oral health status and needs of Canadian adults aged 85 years and over. Spec Care Dentist 1998;18:164-169.

3. Petersen PE, Razanamihaja N. Oral health status of children and adults in Madagascar. Int Dent J 1996;46:41-47.

4. Petersen PE, Kjøller M, Christensen LB, Krustrup U. Changing dentate status of adults, use of dental services, and achievement of national dental health goals in Denmark by the year 2000. J Public Health Dent 2004;64:127135.

5. Krustrup U, Erik Petersen P. Periodontal conditions in 3544 and 65-74-year-old adults in Denmark. Acta Odontol Scand 2006;64:65-73.

6. Carter G, Lee M, McKelvey V, Sourial A, Halliwell R, Livingston $M$. Oral health status and oral treatment needs of dependent elderly people in Christchurch. $N$ Z Med J 2004;21:117(1194):U892. (Abst)

7. Lin HC, Wong MC, Wang ZJ, Lo EC. Oral health knowledge, attitudes and practices of Chinese adults. $J$ Dent Res 2001;80:1466-1470.

8. Petersen PE, Aleksejuniene J, Christensen LB, Eriksen HM, Kalo I. Oral health behavior and attitudes of adults in Lithuania. Acta Odontol Scand 2000;58:243-248.

9. Heft MW, Gilbert GH, Shelton BJ, Duncan RP. Relationship of dental status, sociodemographic status, and oral symptoms to perceived need for dental care. Community Dent Oral Epidemiol 2003;31:351-360.

10. Kulak-Ozkan Y, Ozkan Y, Kazazoglu E, Arikan A. Dental caries prevalence, tooth brushing and periodontal status in 150 young people in Istanbul: A pilot study. Int Dent $J$ 2001;51:451-456.

11. Saydam G, Oktay I. Moller I. Oral health in Turkey-Situation analysis. Report sponsored by Minister of Health and WHO Regional Office for Europe. Seçil Ofset, Istanbul: 1990.

12. Saydam G, Oktay I. Periodontal health status and treatment needs for index age groups in Turkey based on CPITN values. J Nihon Univ Sch Dent 1991;33:147-151. 
13. Pekiner FN, Erçalık S, Dumlu A, Fișekçioḡlu E, Canakçı E, Gümrü B. A comparison of treatments applied before and treatments required in groups of different ages. $J$ Selcuk Univ Dent Fac 2001;11:98-101.

14. Ekanayake L, Weerasekare C, Ekanayake N. Needs and demands for dental care in patients attending the University Dental Hospital in Sri Lanka. Int Dent J 2001;51:67-72.

15. Bradshaw JS. A taxonomy of social need. In: Problems and progress in medical care. McLachlan, G. Editor. London: Oxford University Press; 1972. p. 69-82; (Series 7).

16. World Health Organization: Oral Health Surveys, Basic Methods. $4^{\text {th }}$ ed. Geneva: WHO, 1997.

17. Cutress TW, Ainamo J, Sardo-Infirri J. The community periodontal index of treatment needs (CPITN) procedure for population groups and individuals. Int Dent $J$ 1987;37:222233.

18. Kayser AF, Witter DJ. Oral functional needs and its consequences for dentulous older people. Community Dent Health 1985;2:285-291.

19. Razak IA, Jaafar N. Dental needs, demands and patterns of service utilization in a selected Malaysian urban population. Community Dent Oral Epidemiol 1987;15:188-191.

20. Warnakulasuriya S. Demand for dental care in Sri Lanka. Community Dent Oral Epidemiol 1985;13:68-69.

21. Matee M, Nquvumali H, Lembariti B, Kalyanyama B, Shubi F, Scheutz F. HIV infection, dental treatment demands and needs among patients seeking dental services at the Muhimbili Medical Centre in Dar-es-Salaam, Tanzania. Int Dent $J$ 1999;49:153-158.

22. Robinson PG, Nadanovsky P, Sheiham A. Can questionnaires replace clinical surveys to assess dental treatment needs of adults? J Public Health Dent 1998;58:250-253.

23. Paik DI, Moon HS, Horowitz AM, Gift HC, Jeong KL, Suh SS. Knowledge of and practices related to caries prevention among Koreans. J Public Health Dent 1994;54:205-210. 